\title{
Interferon-alpha 2
}

CrossMark

\section{but not Interferon-gamma serum levels are associated with intramuscular fat in obese patients with nonalcoholic fatty liver disease}

\author{
Giovanni Tarantino ${ }^{1 *}\left(\mathbb{D}\right.$, Susan Costantini ${ }^{2}$, Vincenzo Citro ${ }^{3}$, Paolo Conforti ${ }^{4}$, Francesca Capone ${ }^{2}$, Angela Sorice ${ }^{2}$
} and Domenico Capone ${ }^{5}$

\begin{abstract}
Background: Intramuscular triglycerides (IMTGs) represent an important energy supply and a dynamic fat-storage depot that can expand during periods of elevated lipid availability and a fatty acid source. Ultrasonography (US) of human skeletal muscles is a practical and reproducible method to assess both IMTG presence and entity. Although a crosstalk between cytokines in skeletal muscle and adipose tissue has been suggested in obesity, condition leading to hepatic steatosis (HS) or better defined as nonalcoholic fatty liver disease and cancer, there are still questions to be answered about the role of interferons (IFNs), alpha as well as gamma, and IMTG in obesity. We aimed at discovering any correlation between IFNs and IMTG.
\end{abstract}

Methods: We analysed anthropometric data, metabolic parameters and imaging features of a population of 80 obese subjects with low-prevalence of co-morbidities but HS in relation to IFNs serum levels. A population of 38 healthy subjects (21 males) served as controls. The levels of serum IFNs were detected by a magnetic bead-based multiplex immunoassays.

Results: Serum concentrations of IFN-alpha 2 were increased, while serum levels of IFN-gamma were decreased confronted with those of controls; the severity of IMTG, revealed at US as Heckmatt scores, was inversely predicted by IFN-alpha 2 serum concentrations; IMTG scores were not predicted by serum levels of IFN-gamma; IMTG scores were predicted by HS severity, ascertained at US; HS severity was predicted by visceral adipose tissue, assessed by US, but the latter was not instrumental to IMTG.

Discussion and conclusion: This study has added some pieces of observation about the cytokine network regulating the interplay between IMTG and obesity in obese patients with HS.

Keywords: IFN-alpha, IFN-gamma, IMTG, obesity, NAFLD

\footnotetext{
*Correspondence: tarantin@unina.it

${ }^{1}$ Department of Clinical Medicine and Surgery, "Federico II" University

Medical School of Naples, Naples, Italy

Full list of author information is available at the end of the article
} 


\section{Background}

Intramuscular fat, also known as intramuscular triglycerides, intramuscular triacylglycerol or intramyocellular triacylglycerol (IMTG), but also intramuscular adipose tissue (IntraMAT) and intramyocellular lipid (IMCL), when increased is thought to be linked to increased lipolytic activity in skeletal muscle, contributing to inducing insulin resistance (IR) [1]. Increased muscle TG stores are characterised by cytosolic accumulation of diacylglycerol and acyl-CoA-triglycerides, being lipase regulation central to skeletal muscle lipolysis [2]. Disturbances in pathways of lipolysis may play a role in the development and maintenance of these increased fat stores. Not only is IMTG an important energy supply for skeletal muscle, but represents a dynamic fat-storage depot that can expand during periods of elevated lipid availability [3]. Structural characteristics of IMCL seem to be similar between highly trained endurance athletes, type 2 diabetes patients, and overweight, sedentary men after an overnight fast. This observation is not in agreement with the hypothesis that elevated IMCL deposits are direct responsible for inducing IR [4].

A recent study, carried out to evaluate the exact localisation of IntraMAT, using ${ }^{1} \mathrm{H}$ magnetic resonance spectroscopy or echo intensity (EI) determined by B-mode ultrasonography (US) of human skeletal muscles, has surprisingly suggested that IntraMAT primarily reflects extra-myocellular lipids, not IMCL [5].

Focusing on techniques unravelling IMTG, i.e., EI at US and high-resolution T1-weighted MRI, strong correlations were found between MRI percent fat and muscle EI after correcting for subcutaneous fat thickness [6].

But, apart evidence for being muscle US a practical and reproducible method, another point to be cleared consists in the choice of muscular district to be explored, i.e., the location of the region of interest. Here again, research has confirmed that the EI of biceps brachii and tibialis anterior was higher than that of all other muscles [7].

Beyond considerable insight into the role of IMTG in acute and chronic exercise training [3] and apart the proposed crosstalk between myokines and adipokines in skeletal muscle and adipose tissue [8], at our best knowledge there are no sufficient data about the link of specific cytokines, e.g., interferons (IFNs), alpha as well as gamma, and IMTG in obesity.

Indeed, a piece of evidence shows that IFN-gamma, which is released from inflamed omental adipose tissue, may contribute to the metabolic abnormalities seen in human obesity [9]. What is more, investigation pointed out to increased levels of IFN-gamma in obese subjects that were associated with central adiposity [10]. On the contrary, little research has been conducted to date on the role of IFN-alpha on visceral fat excess [11] and none on IMTG.

The subtype 2 of IFN-alpha was chosen to be evaluated in this study due to its action on memory CD8 cells and cytotoxic CD8 cells, which are activated by adipose tissue, in turn promoting the recruitment and activation of macrophages in this tissue [12], leading to the so-called chronic low grade inflammation, characterized by the abnormal production and activation of certain proinflammatory signalling pathways.

It is known type I IFNs are key cytokines involved in the early immune response to viral infections and it is interesting to evidence that obese subjects tend to have a decreased response to these infections [13] due to a reduced ability to produce IFN-alpha in response to Toll-like-receptors ligands, but its role in the obese without viral infections and its relation to IMTG is not still clarified.

Aiming at finding any correlations between serum concentrations of IFN-alpha 2 as well as IFN-gamma and IMTG, we analysed a population of obese subjects with low-prevalence of co-morbidities but nonalcoholic fatty liver disease (NAFLD) or hepatic steatosis (HS), evaluated by US.

Finally, there is no fresh evidence corroborating the link between NAFLD and IMTG outside exercise intervention [14], taking into account that IMTG is linked to increased BMI and visceral obesity [15] and shares common mechanisms with NAFLD.

\section{Methods \\ Patients}

We carried out a cross sectional type of observational study where at a particular point of time we described characteristics of obese patients without follow-up, with main variables, i.e., IFNs levels and IMTG scores compared to controls.

Specifically, this sub-study used the same original patient sample contained in a previous research [16], but with completely different analytical approaches resulting to be equally valid, according to The International Committee of Medical Journal Editors (ICMJE) at http://www. icmje.org/recommendations/browse/publishing-andeditorial-issues/overlapping-publications.html.

In this study 80 patients, who fulfilled the inclusion criteria and had given previous oral or, when possible, written consensus were selected, comparing them to 38 healthy subjects (control group).

\section{Inclusion criteria}

Obese patients of different grade of obesity, on caloriereduced, low-fat diet and sedentary lifestyle, with low 
prevalence of co-morbidities, such as type 2 diabetes mellitus and hypertension but NALFD, US-documented.

\section{Exclusion criteria}

Patients were excluded if, at the time of blood specimen collection, they self-reported present or antecedent (past month) influenza, cold status, and gastroenteritis or there had been a history of unexplained weight loss in the past months (i.e., $\pm 10 \%$ initial body weight) or recent illness/ chronic disease, and the use of supplements or medications that might have affected body composition or muscle metabolism (e.g., steroids). Sarcopenic obese were ruled out from this selection.

Furthermore, any viral, autoimmune, metabolic liver disease (Wilson disease, hemochromatosis or antitrypsin deficiency) was ruled out by using appropriate testing, according to well-accepted diagnostic guidelines. Celiac disease was excluded by evaluating IgA anti-tissue transglutaminase antibodies. Alcohol abuse was disallowed, following the DSM-IV diagnostic criteria, by means of screening tests such as MAST (Michigan Alcohol Screening Test) and CAGE (Cut down, Annoyed, Guilty, and Eye opener), as well as random tests for blood alcohol concentration and the use of a surrogate marker, e.g., Mean Corpuscular Volume. Patients on antihypertensive drugs, and those treated with metformin or insulin, maintained a balanced therapeutic regimen throughout the study.

\section{Anthropometric evaluation}

The three degrees of obesity (light, moderate, and severe or 1-2-3) were established on the basis of BMI cut-off points of $30-34.9$ and $35-39.9$ and $>40 \mathrm{~kg} / \mathrm{m}^{2}$, respectively.

Visceral obesity was identified by measuring WC at the midpoint between the lower border of the rib cage and the iliac crest. Hip circumference was measured around the widest part of the buttocks, with the tape parallel to the floor, and the waist-to-hip ratio (WHR) was calculated according to the National Institute of Diabetes, Digestive and Kidney Diseases stating that women with WHR of more than 0.8 , and men with more than 1.0 are at increased health risk because of their fat distribution.

\section{Metabolic profile}

The canonical Adults Treatment Panel III was originally chosen to define the metabolic syndrome, considering at least three criteria: plasma glucose concentrations $\geq 100 \mathrm{mg} \mathrm{dL}^{-1}, \mathrm{WC}>102 / 88 \mathrm{~cm}$ (male/female), serum HDL concentration $<50 \mathrm{mg} \mathrm{dL}{ }^{-1}$ for women and $<40 \mathrm{mg} \mathrm{dL}^{-1}$ for men, blood pressure $\geq 130 / 85 \mathrm{~mm}$ $\mathrm{Hg}$, and serum triglyceride concentration $\geq 150 \mathrm{mg} \mathrm{dL}^{-1}$. But, to adhere to ethnic specific values, we added the metabolic syndrome criteria for Europids following the International Diabetes Classification (IDF), i.e., according to the IDF definition for a patient to be defined as having the metabolic syndrome they must have central obesity defined as WC with ethnicity specific values, e.g., for Europe's males and females equal or superior to 94 and $80 \mathrm{~cm}$, respectively), plus any two of the following four factors: Triglycerides $>150 \mathrm{mg} / \mathrm{dL}$ or specific treatment for this lipid abnormality; cholesterol $\mathrm{HDL}<50 \mathrm{mg} / \mathrm{dL}$ for females and $40 \mathrm{mg} / \mathrm{dL}$ for males or specific treatment for this dyslipidemia; systolic and diastolic blood pressure equal or superior to 130 and $85 \mathrm{mmm} \mathrm{Hg}$, respectively; fasting plasma glucose $>100 \mathrm{mg} / \mathrm{mL}$ or previously diagnosed type 2 diabetes mellitus. International Diabetes Federation, 2007; http://www.idf.org.

Triglyceride values of subjects who had fasted at least $12 / 14 \mathrm{~h}$ before the blood draw were evaluated, averaging the results of at least two determinations, made on different days.

\section{Laboratory assessment}

IFNs levels of 78 patients derived by a previously studied 48-cytokine/chemokine panel [16], which was performed on serum samples using a magnetic bead-based multiplex immunoassays (Bio-Plex) (BIO-RAD Laboratories, Milano, Italy) following manufactures' instructions. Data from the reactions were acquired using the Bio-Plex 200 reader, while a digital processor managed data output and the Bio-Plex Manager software returned data as Median Fluorescence Intensity (MFI) and concentration $(\mathrm{pg} / \mathrm{mL})$. Insulin resistance was studied by the HOmeostatic Metabolic Assessment (HOMA) method with the formula: fasting insulin $(\mu \mathrm{U} / \mathrm{mL}) \times$ fasting glucose $(\mathrm{mg} /$ dL)/405 [17]. More than five determinations of HOMA in different situations were taken into account. HOMAderived $\beta$-cell function (HOMA-B\%) was also calculated, using the following formula: $20 \times$ fasting insulin $(\mu \mathrm{U} /$ $\mathrm{mL}) /$ fasting glucose $(\mathrm{mmol} / \mathrm{L})-3.5$ [17]. A stringent value of HOMA $>2$ was introduced as limit of the presence of insulin resistance [18]. We calculated a quantitative insulin sensitivity check index (QUICKI) as 1/ [ $\log$ (fasting insulin $\mu \mathrm{U} / \mathrm{mL}+\log$ (fasting glucose $\mathrm{mg}$ / $\mathrm{dL})$ ], with range between 0.45 in healthy individuals and 0.30 in diabetics [19].

\section{Ultrasonography features}

US measurements were obtained by an Esaote (Genoa, Italy) system. The classification of "bright liver" or hepatic steatosis (HS) was based on the following scale of hyperechogenity: $0=$ absent, $\mathrm{I}=$ light, $2=$ moderate, $3=$ severe, pointing out the difference between the densities of the liver and the right kidney [20], using a Convex Probe, with access to the liver through intercostal spaces along 
the mid-axillary line. Transverse scanning was performed to measure the subcutaneous adipose tissue (SAT) and visceral adipose tissue (VAT) using an eleven and 3.5 $\mathrm{MHz}$ linear probe convex probe, respectively. The SAT was defined as the thickness between the skin-fat interface and the linea alba, avoiding compression, evaluated at the superior tertile of xifo-umbelical line. The VAT was defined as the distance between the anterior wall of the aorta and the internal face of the rectoabdominal muscle perpendicular to the aorta, measured one $\mathrm{cm}$ above the umbilicus. When the aortic walls were not visualized as they were obscured by bowel gas, the Doppler scan was used [21].

Muscle US, performed at the level of the biceps brachii of the left superior arm, is a convenient technique to visualise pathological muscle tissue, as it provides results in real time. Both infiltration of fat and fibrous tissue increase muscle echo intensity; that is, the muscles become whiter on the ultrasound image [22]. To describe muscle echo intensity, Heckmatt and coworkers developed a visual grading scale in which grade I represented normal muscle and grade IV represented a severely increased muscle echo intensity with total loss of bone echo (we chose biceps brachii versus humerus [23]. The levels of brightness of the liver and the biceps brachii, obtained by a single traverse image, were calculated three times directly from the frozen images. The choice of evaluating single traverse image findings was made according to Jenkins et al., who demonstrated that a single transverse imaging and panoramic US imaging are comparable [24].

\section{Indirect calorimetry}

RMR was measured by indirect calorimetry using a canopy system (V max 29 N, Sensor Medics, Anaheim, USA) in a quiet environment and with patients in the supine position for $30 \mathrm{~min}$ before measurement. After a 15-20 min adaptation to the instrument, oxygen consumption and carbon dioxide production were determined for $45 \mathrm{~min}$. Energy expenditure was derived from $\mathrm{CO}_{2}$ production and $\mathrm{O}_{2}$ consumption with the appropriate Weir formula neglecting protein oxidation [25]. BMR, expressed as $\mathrm{kcal} / 24 \mathrm{~h}$, was adjusted for changes in fat-free mass (FFM), which was evaluated by single-frequency bioimpedance analysis (BIA) obtaining a RMR/ FFM ratio, expressed as kcal/ $24 \mathrm{~h}$ *kg of body. Fat mass and FFM percentage were estimated using the device's standard built in prediction equations and were displayed on the machine and printed out [26].

The BIA assessment was performed between 10:00 A.M. and 4:00 P.M. The participants were required to fasting and avoiding vigorous exercise for at least $1 \mathrm{~h}$ before BIA assessment. BIA measurements were performed while patients stood barefoot on the metal surface of the device and kept their arms loose and in parallel with the body. Measurement took 1-2 $\min (\mathrm{s})$ for each patient, and results were automatically printed out from the device. Body fat percentage, FFM, and total body water were measured by BIA. The measurements were recorded by well-trained staff, using a BIACorpus RX 4000 (Medi-Cal Healthcare GmbH, Karlsruhe, Germany). Sarcopenic obesity was defined minus of two lower quintiles of muscle mass $\left(<9.12 \mathrm{~kg} / \mathrm{m}^{2}\right.$ in men) and $\left(<6.53 \mathrm{~kg} / \mathrm{m}^{2}\right.$ in women) and two highest quintiles of fat mass ( $>37.16 \%$ in men) and ( $>40.01 \%$ in women) according to NHANES II [27].

\section{Control group}

Though IFN-alpha 2 is one of cytokines/chemokines not detected in any group of age of healthy subjects, either because they are under the lower limit of detection or because they are not produced [28] we took into account values of a population of 38 young healthy subjects to reduce the type I error. The control arm provided information when analysing difference of IFN-gamma levels in groups, too.

\section{Statistics}

Data, derived from a normally distributed population, were given as mean plus SD. Variables not normally distributed or ordinals are expressed as median plus 25-75 interquartile range (IQR). The difference in medians was assessed by the Mann-Whitney test. The two-way crosstabulation was set by the Pearson correlation coefficient (Chi square). The Kruskal-Wallis equality-of-populations rank test was as used to evaluate differences when dealing with more that two variables.

The Spearman's coefficient of rank correlation (rho) was employed to analyse the basic correlation between some data.

At univariate analysis, the linear regression analysis (ordinary least squares or OLS) was used evaluating the coefficient with its standard error, $95 \%$ confidence intervals $(\mathrm{CI})$, the $t(t-v a l u e)$ and $\mathrm{R}^{2}$. In suspicion of heteroscedasticity, i.e., when there were sub-populations that have different variabilities from others in the homoscedastic model, and having detected the presence of few outliers, we analysed the correlation by the robust regression, using Least Absolute Deviations (LAD) Regression.

Contextually was conducted a residual analysis, a "residuals versus fits plot". It is a scatter plot of residuals on the y axis and fitted values (estimated responses) on the $\mathrm{x}$ axis. The plot was used to detect non-linearity, unequal error variances, and outliers.

A simultaneous quantile regression was applied as a way to discover more useful predictive relationships 
between variables (bootstrap method). Quantile regression is more robust to non-normal errors and outliers.

At multiple linear regression also the factor Beta $(\beta)$ was added.

An ordered probit model was employed to estimate relationships between an ordinal dependent variable (IMTG) or HS at US and a set of independent variables. These ordinal variable are variables that are categorical and ordered, expressed as severity score (I-IV) for the former or severity grade for the latter [1-3]. The output showed the coefficients, their standard errors, the z-statistic (also called a Wald z-statistic), and the associated P-values.

In a specific circumstance a Bayesian inference computed the posterior probability, expressed as mean, SD, Montecarlo standard error or MCSE, median and credibility intervals.

To highlight light unobserved confounding variables two methods were adopted: (i) Testing for mediation was performed as a four step approach in which several regression analyses were performed; the significance of the coefficients were examined at each step to study the so-called indirect effect [29]. (ii) The method of Instrumental Variables (IV) was utilised to estimate causal relationships. A valid instrument induces changes in the explanatory variable (covariate) but has no independent effect on the dependent variable, allowing to uncover the causal effect of the explanatory variable on the dependent variable. An instrument is a variable that does not itself belong in the explanatory equation but is correlated to the endogenous explanatory variables, conditional on the value of other covariates. The type of model was random effects and the estimator was the Baltagi-Changone.

The Factor Analysis was applied to detect the structure in the relationships among variables, selecting a subset of variables having the highest correlations with the principal component factors. In order to select a subset of variables, firstly Cattell Screen plot, with relative eigenvalues, was performed to screen the real factors, which resulted to be three. Secondly, extraction of the main components amounted to a variance maximizing (varimax) the rotation of the original variable space. The critical value was calculated by doubling Pearson's correlation coefficient for $1 \%$ level of significance (5.152)/square root of patients minus 2 (n 78), i.e., 0.583 . In bold will be shown the main components for any single factor, with a value superior to the critical one.

A closed form estimator of the uniqueness (unique variance) is proposed. It has analytically desirable properties, i.e., consistency, asymptotic normality and scale invariance. The concordance correlation coefficient $\left(\rho_{c}\right)$, which measures precision and accuracy, was adopted to evaluate the degree of pair observations at US.
The power of this study was calculated on the difference of means of IFN-alpha and IFN-gamma levels between the obese and control group. In order to deepen this aspect, a further power analysis was performed using a slope test in the linear regression between the IFNalpha levels and the IMTG scores.

Stata 15.1, Copyright 1985-2017, was the program on which we run statistics.

\section{Results}

The controls consisted of $17 / 21$ healthy females/males with a BMI of $21(20-21)$ and $23(22-23)$, respectively. Their WC was $78(78-79)$ and $94(92-93) \mathrm{cm}$, respectively (values expressed as median plus IQR). Characteristics of the obese are shown in Table 1.

The median plus IQR for IFN-alpha 2 of healthy subjects was $2 \mathrm{pg} / \mathrm{mL}(0-2)$, the age-related reference intervals are shown in Fig. 1.

An interesting finding was that IFN-alpha 2 levels of obese patients were found to be significantly increased when compared to those of controls, i.e., $121.9 \mathrm{pg} /$ $\mathrm{mL}(103.5-135.8)$ versus $2(0-2)$, median plus IQR, $\mathrm{P}=<0.0001$, the Mann-Whitney test.

The median plus IQR for IFN-gamma of healthy subjects was $547.5 \mathrm{pg} / \mathrm{mL}$ (479-670, the age-related reference intervals are shown in Fig. 2.

The obesity degrees (1,2 and 3$)$, to which belonged 8 , 26 and 46 patients respectively, did non show different distribution compared to gender, Pearson's Chi square, $\mathrm{P}=0$. 74. IFN-alpha 2 levels were not significantly different among the three obesity degrees, $\mathrm{P}=0.24$, KruskalWallis equality-of-populations rank test.

Noteworthy, IFN-gamma levels in obese were lower than those of healthy subjects, i.e., $158 \mathrm{pg} / \mathrm{mL}$ (56390) versus $547.5 \mathrm{pg} / \mathrm{mL}$ (479-670), median plus IQR, $\mathrm{P}<0.001$, the Mann-Whitney test.

IMTG presence in our population was characterised by a light-moderate score of severity, as reported in Table 1.

The score of IMTG was not different when controlled for gender (Table 2), while the severity of HS at US was related to the obesity degree (Table 3 ). Finally, the score of IMTG was not dependent from the obesity degree (Table 4).

\section{Relationships}

First of all, IFN-alpha 2 and IFN-gamma levels were not correlated, $\mathrm{P}=0.67$, Spearman's rank correlation.

IMTG score were negatively predicted by IFN-alpha 2 levels at robust regression and ordered probit regression, Coeff. $=-0.0149424$ Std. err. $=0.0033541, \mathrm{t}=-4.29$, $\mathrm{P}=0.0001$, Conf. interval $=-0.0220211-0.0078638$ and Coeff. $=-0.0312922$, Std. err. $=0.0090407, Z=-3.46$, 
Table 1 Data of the studied patients

\begin{tabular}{|c|c|c|c|}
\hline Age (years) & $46(34-53)$ & $\begin{array}{l}\text { Gender } \\
\text { Males/females (n) }\end{array}$ & $36 / 44$ \\
\hline \multirow[t]{2}{*}{ BMl } & $42(38-47)$ & WC (Males) cm & $126(121-135)$ \\
\hline & & WC (Females) cm & $119(110-128)$ \\
\hline WHR males & $0.98(0.96-1.05)$ & Obesity & \\
\hline WHR females & $0.95(0.93-0.97)$ & Grade $|/||/|||(n)$ & $8 / 26 / 46$ \\
\hline HOMA & $2.78(1.85-4.18)$ & HOMA-B \% & $37.11(22.4-49.8)$ \\
\hline QUICKI & $0.32(0.31-0.35)$ & Insulin $(\mu \mathrm{U} / \mathrm{mL})$ & $11(7.1-15.8)$ \\
\hline $\mathrm{HDL}$ (males) (mg/dL) & $42.7 \pm 8.98$ & $\mathrm{HDL}$ (females) (mg/dL) & $49 \pm 13$ \\
\hline Triglycerides (mg/dL) & $123.5(83.5-188)$ & $\operatorname{ALT}(U / L)$ & $28(21.5-39)$ \\
\hline Gamma-GT (U/L) & $25(16.5-42.5)$ & $\operatorname{hsCRP}(\mathrm{mg} / \mathrm{mL})$ & $0.56(0.27-1.3)$ \\
\hline Ferritin (males) (ng/mL) & $167.5(85-234.5)$ & Ferritin (females) (ng/mL) & $41.5(20-69)$ \\
\hline Fibrinogen (g/L) & $306 \pm 74.7$ & $\begin{array}{l}\text { Cholesterol } \\
\mathrm{mg} / \mathrm{dL}\end{array}$ & $190 \pm 36.1$ \\
\hline Fat mass $\%$ & $52 \pm 7.5$ & FFM\% & $56.2(41-67)$ \\
\hline \multirow[t]{2}{*}{ RMR/FFM/kg } & $38.7(33.9-43)$ & HS at US & \\
\hline & & Grade 1/2/3 (n) & $22 / 50 / 8$ \\
\hline VAT at US (cm) & $7.5(6-9.4)$ & SAT at US (cm) & $2.6(2.1-3.1)$ \\
\hline \multirow[t]{2}{*}{ IMTG score } & $2.25(2,3)$ & MS (APT III) yes/not (n) & $51 / 29$ \\
\hline & & MS (IDF) yes/not (n) & $51 / 29$ \\
\hline IFN-alpha 2 pg $^{\mathrm{a}}$ & $121.9(103.5-135.8)$ & IFN-gamma $(p g / m L)^{a}$ & $158(56-390)$ \\
\hline
\end{tabular}

MS evaluated by ATP III and IDF criteria gave the same prevalence

IMTG intramuscolar triglycerides, VAT visceral adipose tissue, SAT subcutaneous adipose tissue, US ultrasound, WHR Waist-To-Hip Ratio, WC waist circumference, RMR resting metabolic rate, FFM fat-free mass, MS metabolic syndrome, HS hepatic steatosis, $n$ number of patients

a 78 patients were examined for IFNs. The mean plus/minus SD of IFN-alpha 2a levels of the obese was $120.1 \pm 24.6$

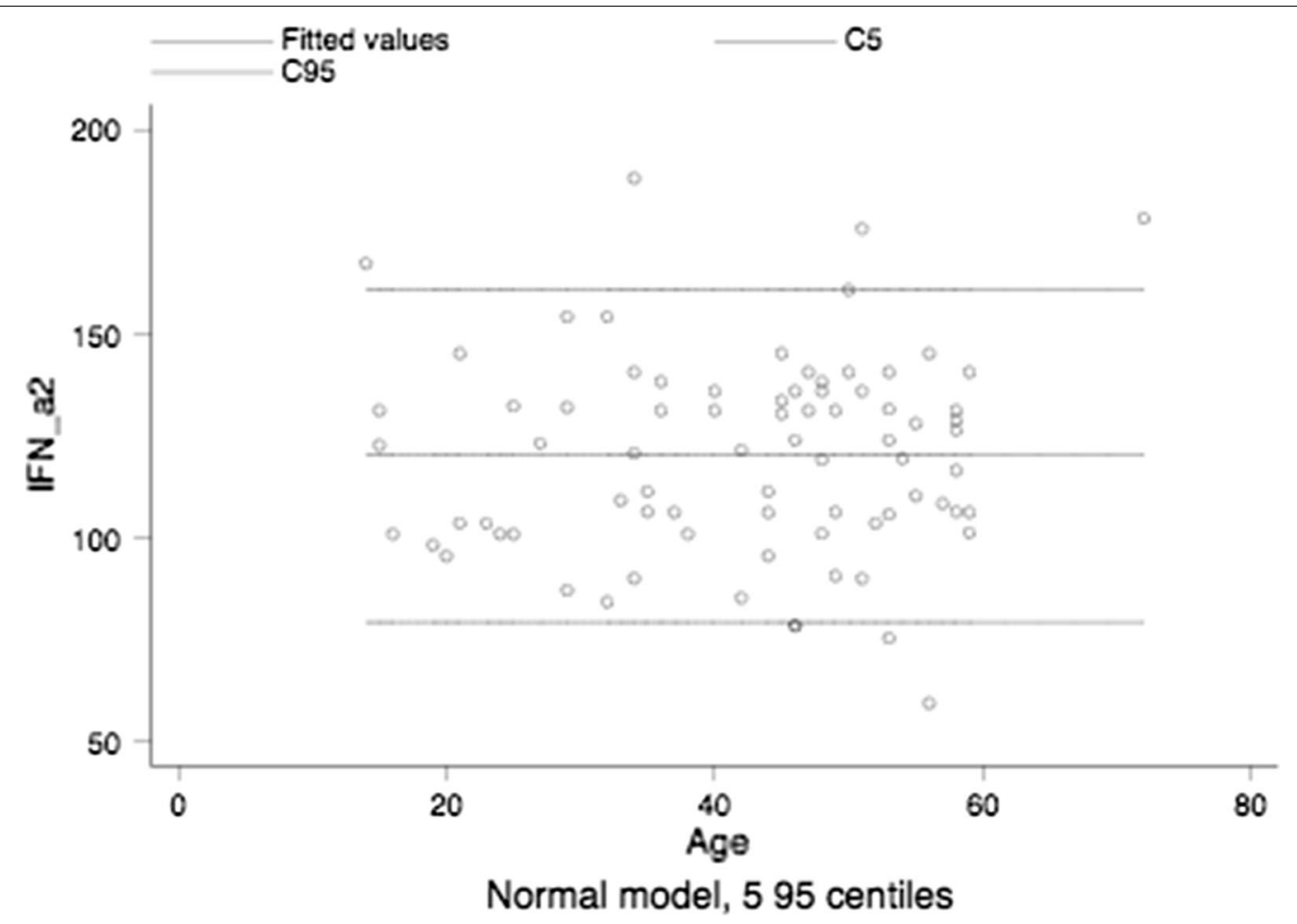

Fig. 1 Age-related reference intervals of IFN-a2 in healthy subjects 


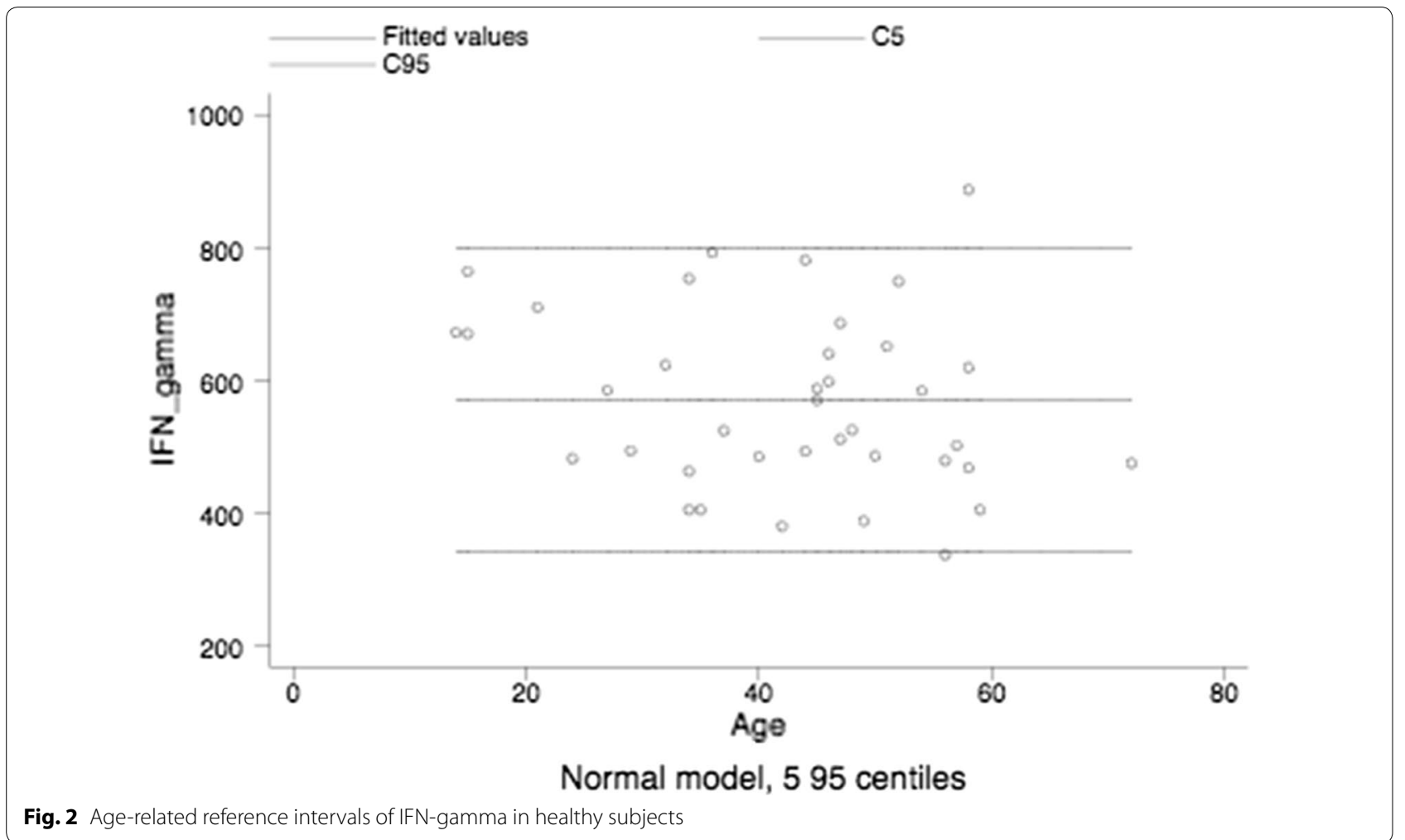

Table 2 Correlation between IMTG and gender

\begin{tabular}{llllll}
\hline Gender & \multicolumn{3}{l}{ IMTG scale (scores) } & & Total \\
\cline { 2 - 5 } & I & II & III & IIII & \\
\hline Females & 7 & 14 & 16 & 7 & 44 \\
Males & 3 & 10 & 14 & 9 & 36 \\
\hline
\end{tabular}

Two-way cross-tabulation, Pearson Chi square, $\mathrm{P}=0.6$; total: number of patients

Table 3 Correlation between obesity severity and hepatic steatosis grade

\begin{tabular}{llrrr}
\hline HS at US grade & \multicolumn{2}{c}{ Obesity degrees } & Total \\
\cline { 2 - 4 } & $\mathbf{1}$ & $\mathbf{2}$ & $\mathbf{3}$ & \\
\hline 1 & 5 & 9 & 8 & 22 \\
2 & 3 & 17 & 30 & 50 \\
3 & 0 & 0 & 8 & 8 \\
\hline
\end{tabular}

Two-way cross-tabulation, Pearson chi square $=12.5536, \mathrm{P}=0.014$; total: number of patients

$\mathrm{P}>|\mathrm{z}|=0.001$, Conf. interval $=-0.0490116-0.0135729$, respectively, Fig. 3.

The residual-versus-fitted plot, Fig. 4, shows that fitted values do not have an obvious trend of failure. Conclusively, there is no problems of heteroskedasticity as residuals appear to have the same variance everywhere.
When adjusting for gender and age the prediction of IFN-a2 on IMTG overlapped the previous ones obtained by two methods (robust regression and ordered profit regression), i.e., Coeff. $=-0.0149346$, Std. err. $=0.0037878, t=-3.94, P=0.000$, Conf. inter$\mathrm{val} .=-0.0224818$ to -0.0073873 .

IMTG grades were not predicted by IFN-gamma levels, analysing them both by LAD regression and order profit regression, i.e., Coeff. $=0.0000239$, Std. Err $=0.0003695$, $\mathrm{t}=0.06, \quad \mathrm{P}=0.94995 \%$, Conf. interval $=-0.0007118$ -0.0007596 and Coeff. $=0000152$, Std. err. $=0004215$, $\mathrm{z}=0.04, \mathrm{P}>|\mathrm{z}|=0.971$, Conf. interval $=-0.0008109$ to -0.0008412 , respectively.

Table 5 shows results of the simultaneous quantile regression (bootstrap method), highlighting that IMTG scores are predicted exclusively by intermediate and upper quantiles of IFN-alpha 2 levels.

Although IFN-alpha 2 was playing per se a significant role in predicting fibrinogen in the mediation method, its role was completely excluded as evident in Table 6 .

The ordered probit regression showed that IMTG was predicted by HS at US as well as HS was predicted by VAT, Table 7 and Fig. 5.

To clarify this important aspect, instrumental-variables regression excluded the role of the confounding variable (VAT) as mediator between IMTG and HS, as evident in Table 8. 
Table 4 Correlation between obesity severity and IMTG

\begin{tabular}{llrrr}
\hline IMTG score & \multicolumn{3}{l}{ Obesity degrees } & Total \\
\cline { 2 - 4 } & $\mathbf{1}$ & $\mathbf{2}$ & $\mathbf{3}$ & \\
\hline I & 0 & 4 & 6 & 10 \\
II & 3 & 10 & 11 & 24 \\
III & \multicolumn{1}{|l|}{} & 9 & 17 & 30 \\
\hline
\end{tabular}

Prevalence of moderate/severe grade of IMTG, i.e. 54 out of 80 patients $=67.5 \%$; Two-way cross-tabulation, Pearson square $=4.9252, \mathrm{P}=0.553$

Total: number of patients. Hepatic steatosis (HS) at UltraSonography (US)

At multivariate analysis, among VAT, SAT, WC, WHR, BMI only VAT predicted IMTG, i.e., Coeff. $=0.1384446$, Std. err. $=0.0582611, \quad \mathrm{t}=2.38 ; \quad \mathrm{P}>|\mathrm{t}|=0.020, \quad 95 \%$ [Conf. interval] 0.0223568-0.2545323.

No prediction of IMTG by HOMA, HOMA-B \% and QUICKI ( $\mathrm{P}=0.56,0.15$ and 0.71 , respectively).

The finding concerning no link between IR and IMTG was confirmed by a more powerful tool evaluating whether IMTG might be predicted by HOMA, i.e, Coeff. $=0.0219949$; Std. err. $=0.0367399 \mathrm{z}=0.60$; $\mathrm{P}>|\mathrm{z}|>0.549$; Conf. interval $=-0.050014$ to 0.0940038 ; ordered profit regression, robust method.
There was no prediction of IMTG by fat mass, FFM and RMR/FFM ratio $(\mathrm{P}=0.550,0.232$ and 0.069 , respectively, evaluated as ordered profit regression).

By the same technique, HS at US was not predicted by IFN-alpha levels $(\mathrm{P}=0.079)$.

As expected, at univariate analysis HOMA-B \% was predicted by HOMA: Coeff. 8.200134, Std. err. $=1.072445, \quad \mathrm{t}=7.65, \quad \mathrm{P}>|\mathrm{t}|=0.000, \quad 95 \% \quad$ Conf. interval $=6.06506-10.33521$.

Studying the hidden relationships between various variables comprehending anthropometric measures, fat and free-fat masses, US features of central, peripheral fat and intramuscular distribution, it is confirmed the link between IFN-a2 and IMTG (as evident in factor 3) as well as other parameters, Table 9.

Bayesian inference computing the posterior probability to appreciate the good level of confidence of the main linear regression results, i.e., IMTG/IFN-a2, was shown in Table 10.

The intra/inter-observational variability of UltraSound estimations was not significant, the mean difference being 1.9, 2.9, 2.4 and 3.1\%, and 2.3, 3.1, 3. 9 and 3.1\% for the HS, IMTG, SAT, and VAT, respectively, with a $\rho_{\mathrm{c}}$ of 0.91 .

Finally, the study turned out to be sufficiently powered (alpha $=0.01$, power $=0.99)$ considering the sample size

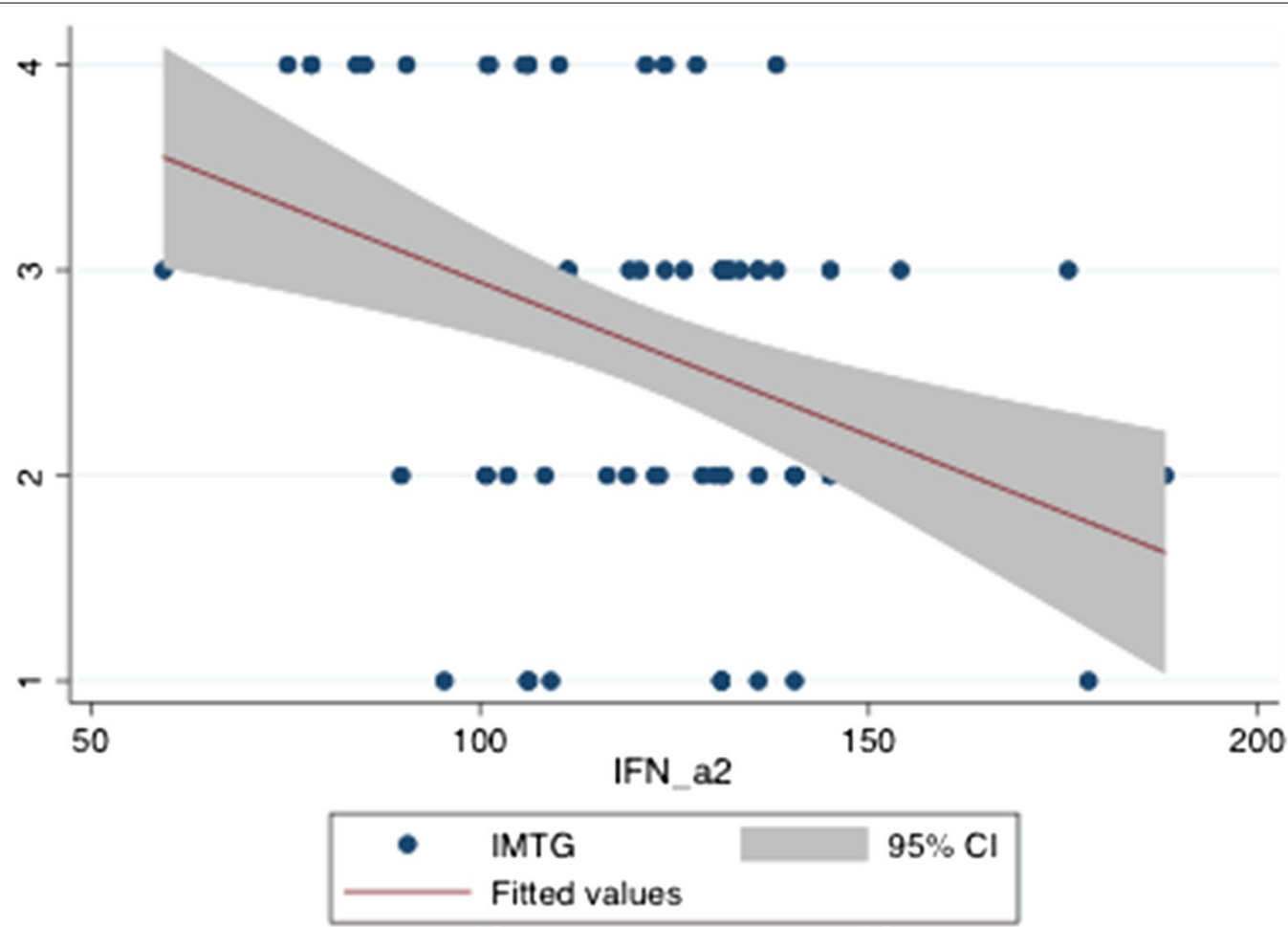

Fig. 3 Prediction of IMTG scores by IFN-alpha concentrations 


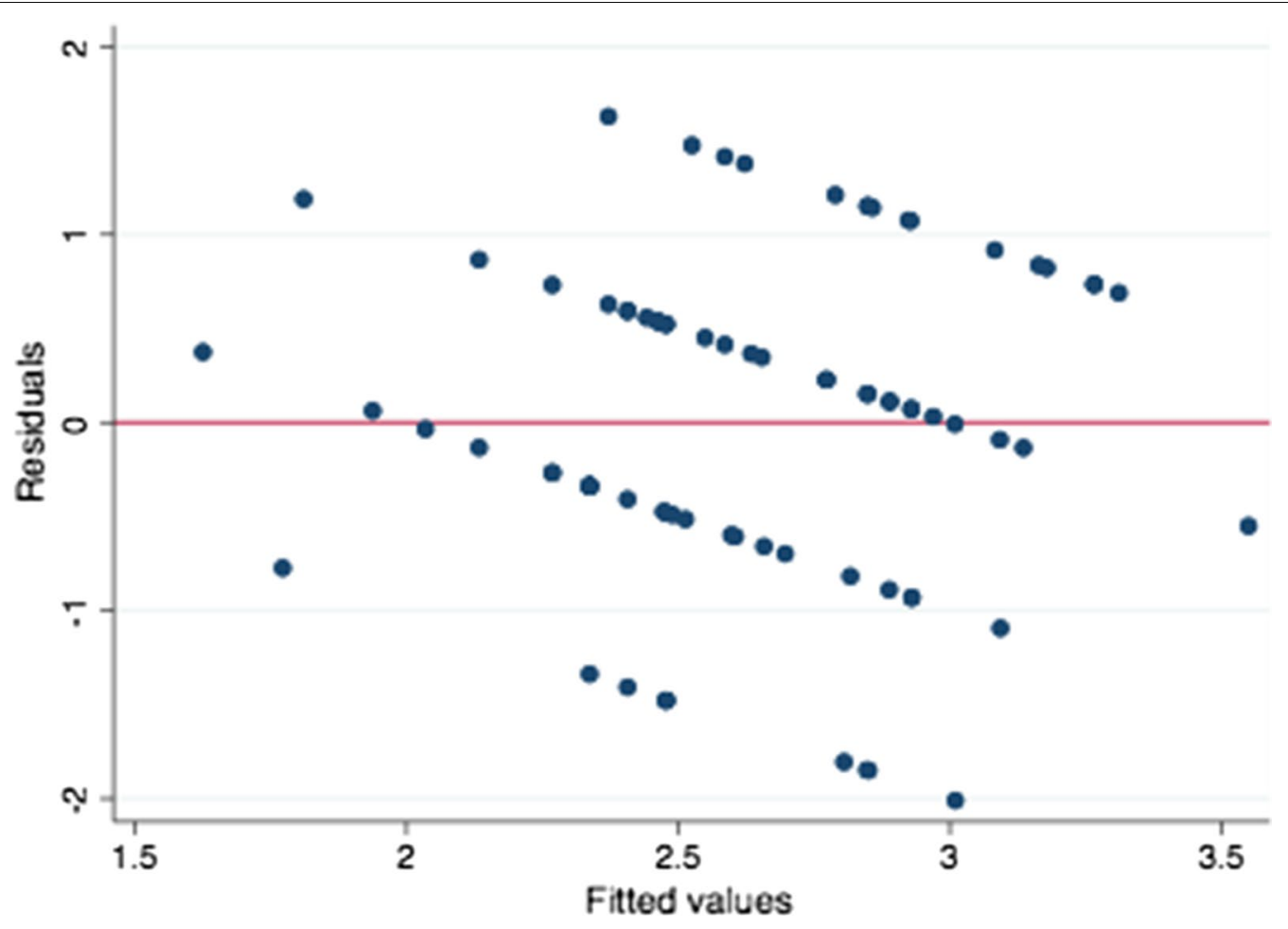

Fig. 4 Regression diagnostics, i.e., residuals plotted against the fitted values

Table 5 Quantile regression for predicting IMTG by IFN-alpha

\begin{tabular}{llllll}
\hline IMTG & Coeff. & Std. err. & t & P & $\mathbf{9 5 \% C l}$ \\
\hline q25 & & & & & -0.0072308 to 0.0072308 \\
IFN-alpha 2 & 0 & 0.0036305 & 0.00 & 1.000 & -0.0302554 to 0.0047389 \\
q50 & & -2.58 & 0.08 & -0.0272471 to 0.0090637 \\
IFN-alpha 2 & -0.0174917 & 0.004081 & & 0.000 & -3.98 \\
q75 & -0.0181554 & 0.0045649 & & & \\
IFN-alpha 2 & & & & & \\
\hline
\end{tabular}

Simultaneous Quantile regression Bootstrap SE (200 replications). The prediction of IMTG by IFN-alpha 2 levels is confined to their intermediate and upper quantiles Cl confidence interval

Table 6 Mediation methods for predicting variables

\begin{tabular}{|c|c|c|c|c|c|}
\hline & Coeff. & Std. err. & $\mathrm{t}$ & $\mathbf{P}$ & [95\% Conf. interval] \\
\hline \multicolumn{6}{|c|}{ At Univariate analysis (Robust regression) } \\
\hline IMTG/IFN-alpha 2 & -0.0151912 & 0.0043683 & -3.48 & 0.001 & -0.0238932 to .0064892 \\
\hline Fibrinogen/IFN-alpha 2 & -0.1085108 & 0.0262153 & -4.14 & 0.000 & -0.1607232 to .0562985 \\
\hline IMTG/Fibrinogen & 0.001491 & 0.0014679 & 1.02 & 0.313 & -0.0014314 to .0044134 \\
\hline \multicolumn{6}{|l|}{ At MULTIPLE regression } \\
\hline IMTG/Fibrinogen & -0.0002527 & 0.0015718 & -0.16 & 0.873 & -0.0033839 to -0.0028785 \\
\hline IMTG/IFN-alpha 2 & -0.0151912 & 0.0038637 & -3.93 & 0.000 & -0.022888 to .0074944 \\
\hline Beta of IFN-alpha 2 & \multicolumn{5}{|c|}{-0.39 ; beta of Fibrinogen $=-0.019$} \\
\hline
\end{tabular}

The mediation effect of fibrinogen was excluded

The first variable the two showed is the dependent one 


$\begin{aligned} & \text { Table } 7 \text { Ordered probit } \\ & \text { of a confounding variable }\end{aligned}$
$\begin{array}{rllll}\text { Coeff. } & \text { Std. err. } & z & P>|z| & \begin{array}{l}\text { [95\% Conf. } \\ \text { interval] }\end{array}\end{array}$

\begin{tabular}{llllll}
\hline d.v.: IMTG scores & & & & & \\
i.v.: HS grade & 0.6427975 & 0.215061 & 2.99 & 0.003 & $\begin{array}{c}0.2212858 \text { to } \\
1.064309\end{array}$ \\
$\begin{array}{llllll}\text { d.v.: HS grade } \\
\text { i.v.: VAT } & 0.8153024 & 0.1584942 & 5.14 & 0.000 & 0.5046595 \text { to } \\
\end{array}$ & & & & & 1.125945
\end{tabular}

In these two regressions there is a suspicion of a confounding variable or covariate that is VAT

d.v. dependent variable, i.v. independent variable

of the two studied populations on the basis of different means of IFNs. Furthermore, the estimated sample size for a linear regression slope test between IFNA levels and IMTG scores was inferior to that of our obese group.

\section{Discussion}

This study was designed to investigate any correlation of IFN-alpha 2a and IFN-gamma to IMTG in obese patients with US-detected HS or NAFLD.

Stating the major findings of our study, we should drawn attention on: (i) serum concentrations of
IFN-alpha 2 were increased, while serum levels of IFN-gamma were decreased confronted with those of controls; (ii) the severity of IMTG, revealed at US as Heckmatt scores (I-IV) was negatively predicted by IFNalpha 2 serum concentrations; (iii) IMTG scores were not predicted by serum levels of IFN-gamma; (iv) IMTG scores were predicted by HS severity ascertained by a US scale (grades 1-3); (v) HS severity was predicted by VAT but the latter was not instrumental to IMTG.

To try to explain the possible mechanisms of the core finding, i.e., the inverse association between IFN-alpha 2 and IMTG we can focus on serum lipid profile creating sort of parallelism between other situations/diseases in which increased concentrations of this cytokine were found and our obese patients.

Previous experiments in vitro showed that IFN-alpha inhibits lipoprotein lipase (LPL) activity directly or indirectly by inducing specific cytokines [30, 31]. In addition, increase in lipogenesis and VLDL secretion in the liver by IFN-alpha may contribute to hypertriglyceridemic subjects, as evident in cultured hepatocytes [32-34] and in patients on IFN-alpha therapy [35].

In contrast with aforementioned studies, other reports indicate that the elevated IMTG content found in obese women is not due to an up-regulation of key lipogenic proteins or to the suppression of lipolytic proteins [36].
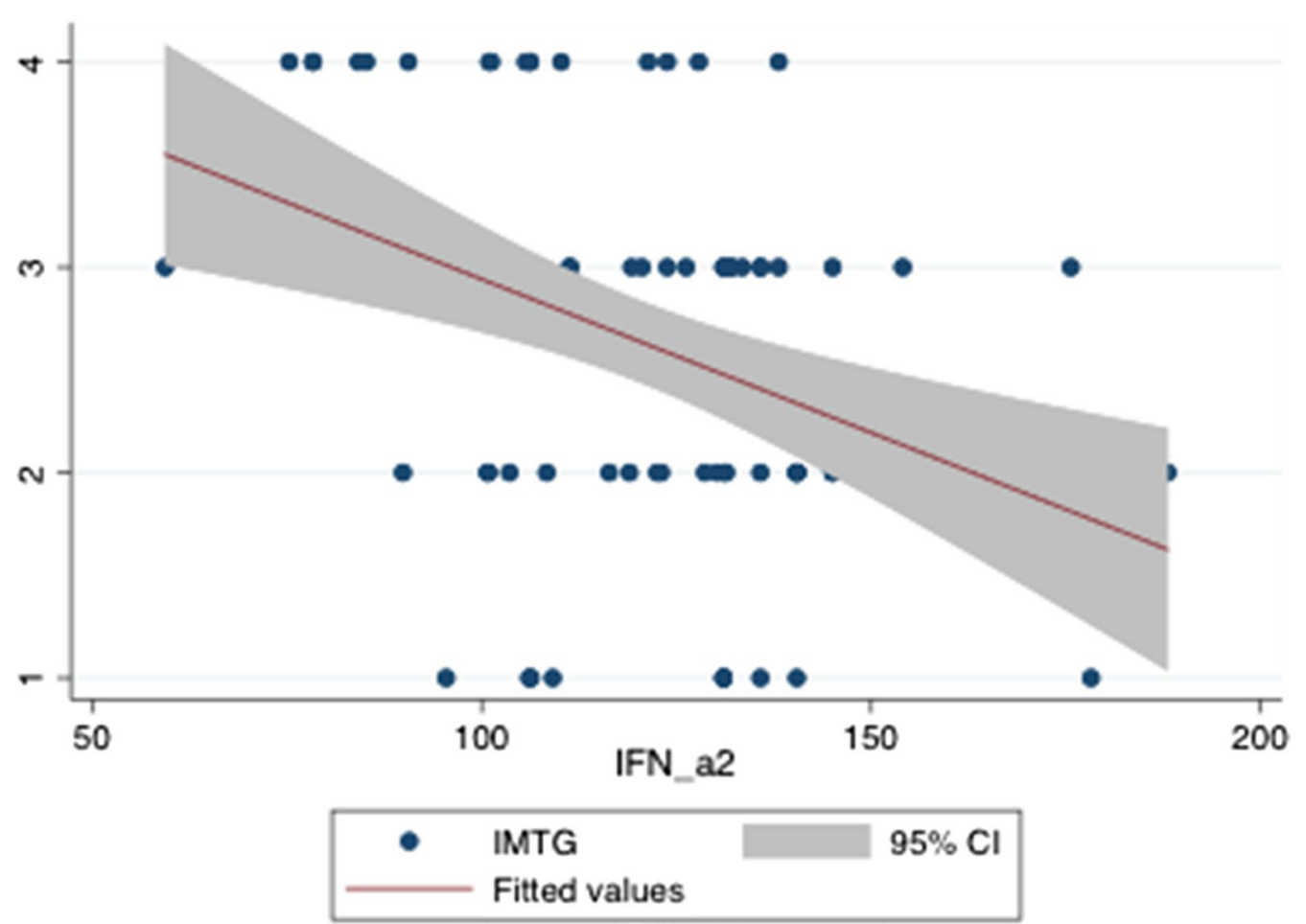

Fig. 5 Prediction of IMTG scores by HS at US grades 


\section{Table 8 Instrumental-variables regression for panel data (Baltagi-Chang estimator)}

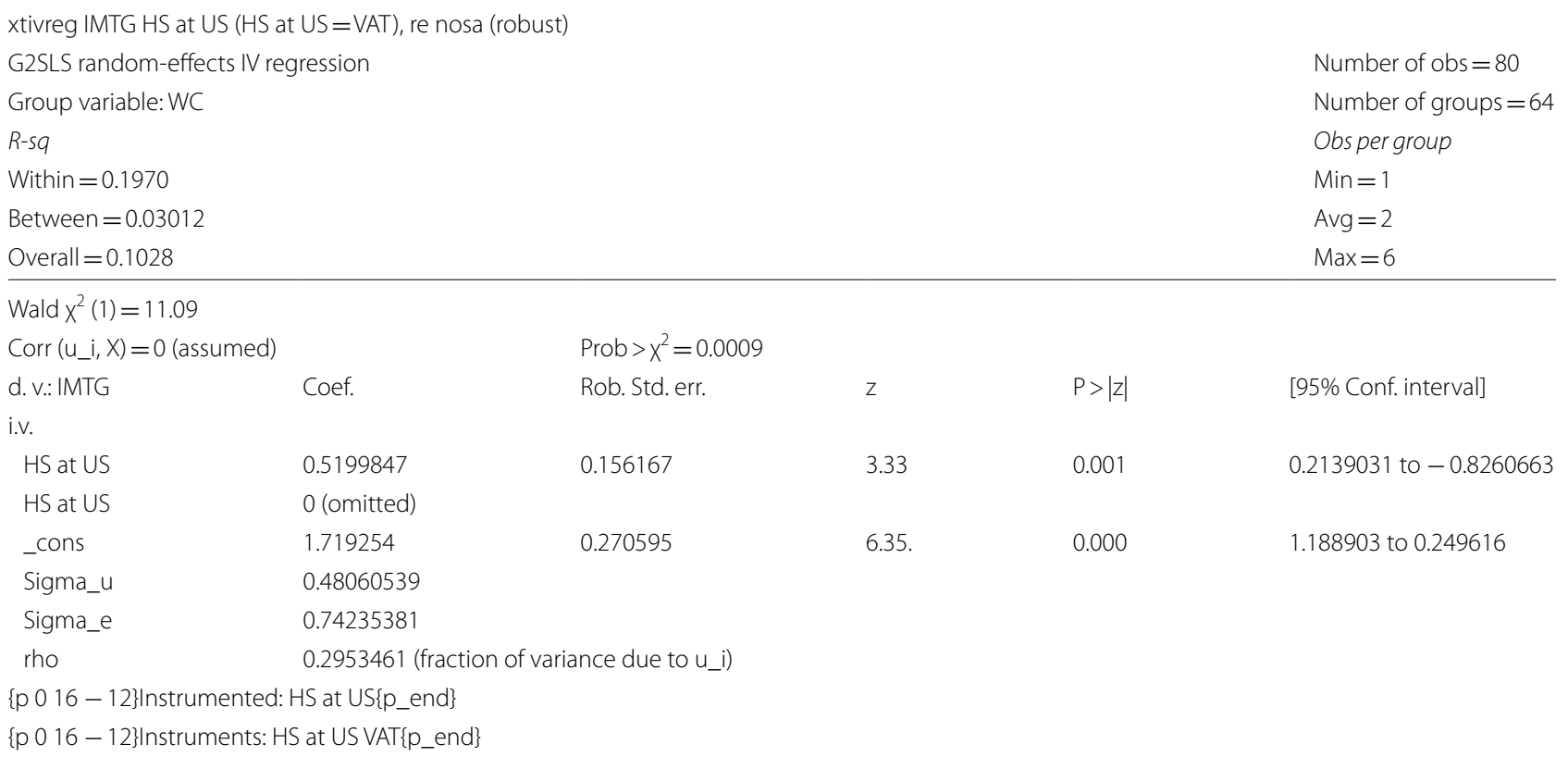

The instrument (VAT) cannot be correlated with the dependent (IMTG) in the explanatory equation. In other words, the instrument cannot suffer from the same problem as the original predicting variable (IMTG predicted by HS at US). If this condition is met, then the instrument is said to satisfy the exclusion restriction. As grouping variable was chosen an index of visceral adiposity, i.e., WC

IMTG intramusclolar triglycerides, HS at US hepatic steatosis at Ultrasonography, VAT visceral adipose tissue, d.v. dependent variable, i.v. independent variable

\section{Table 9 Factor analysis}

\begin{tabular}{|c|c|c|c|c|}
\hline Variable & Factor 1 & Factor 2 & Factor 3 & Uniqueness \\
\hline \multicolumn{5}{|c|}{ Rotated factor loadings (pattern matrix) and unique variances } \\
\hline $\mathrm{BMI}$ & 0.8803 & 0.2118 & -0.0337 & 0.1791 \\
\hline Obesity grade & 0.7365 & 0.3327 & 0.0669 & 0.3424 \\
\hline WC & 0.8641 & -0.1363 & 0.0146 & 0.2345 \\
\hline WHR & -0.1507 & -0.3176 & 0.5373 & 0.5878 \\
\hline Fat mass\% & -0.1197 & -0.9089 & 0.0098 & 0.1594 \\
\hline IMTG & 0.2645 & -0.1249 & 0.6626 & 0.4753 \\
\hline SAT & 0.4182 & 0.4665 & 0.0325 & 0.6064 \\
\hline VAT & 0.7446 & -0.2465 & 0.2437 & 0.3255 \\
\hline IFN-alpha 2 & -0.0214 & -0.1072 & -0.8050 & 0.3400 \\
\hline $\mathrm{RMR} / \mathrm{FFM} / \mathrm{kg}$ & -0.1561 & 0.7631 & -0.0293 & 0.3925 \\
\hline IFN-gamma & 0.1082 & 0.1913 & 0.3257 & 0.8457 \\
\hline Factor rotation matrix & Factor 1 & Factor2 & Factor3 & \\
\hline \multicolumn{5}{|c|}{ The extracted components explain nearly 60 (59.19)\% of variability } \\
\hline Factor 1 & 0.9414 & 0.2736 & 0.1971 & \\
\hline Factor 2 & 0.1674 & -0.8865 & 0.4313 & \\
\hline Factor 3 & 0.2928 & -0.3731 & -0.8804 & \\
\hline
\end{tabular}

The critical value was calculated by doubling Pearson's correlation coefficient for $1 \%$ level of significance (5.152)/square root of patients minus 2 (78), i.e., 0.583 . In italics it will be shown the main components for any single factor, with a value superior to the critical one. HS was excluded due to collinearity with IMTG anVAT. The link between IFN-alpha 2 and IMTG (factor 3 ) as well as significative parameters in factors one and two are shown in italics text 
Table 10 Bayesian inference computing the posterior probability

\begin{tabular}{llllcc}
\hline & Mean & Std. dev. & MCSE & Median & [95\% Cred. interval] \\
\hline $\begin{array}{l}\text { Equal-tailed } \\
\text { d.v.: IMTG }\end{array}$ & & & & \\
i.v.: IFN-alpha 2 & -0.0151632 & 0.004142 & 0.000122 & -0.0151286 & -0.0229845 to 0.0069051 \\
Cons & 4.46095 & 0.5110447 & 0.016827 & 4.460191 & 3.442408 to 5.436929 \\
Sigma $^{2}$ & 0.8045077 & 0.1360474 & 0.003159 & 0.7905886 & 0.5719823 to 1.09947 \\
\hline
\end{tabular}

Default priors are used for model parameters. Simulations introduce an additional level of uncertainty to the accuracy of the estimates. Monte Carlo standard error (MCSE), which is the standard error of the posterior mean estimate, measures the simulation accuracy

Using Bayesian linear regression we asked which parts (if any) of its fit to the data was it confident about, and which parts were very uncertain (perhaps based entirely on the priors). Looking at the ratio of MCSE to Std. dev. (in this case $0.000122 / 0.004142=0.029$ ) we have $2.9 \%$, i.e., minus than $5 \%$ (significant auto correlation)

Little of the posterior variability is due to simulation, thus the model is valid

d.v. dependent variable, i.v. independent variable

Although IMTG synthesis rates were previously related to insulin sensitivity [2], we authors did not find a link between IMTG and IR. Indeed, we did not evaluate IR by glucose clamp technique but surrogate markers, even though quite reliable [37].

Relating our findings to those of available studies, we emphasise that in a research on HIV-1-infected men, a significant positive correlation was found between accumulation of IFN-alpha and increased levels of cholesterol, TG, VLDL cholesterol, VLDL TG, ApoB and ApoB-ApoA1 ratio [11], raising suspicion of active lipogenesis. Nevertheless, we should stress that the study of Teran-Cabanillas et al. showed that obese subjects have a decreased ability to produce IFN-alpha in response to TLR ligands [13].

Concerning the levels of IFN-gamma in our population we recognise that a comparison with results by Schmidt et al. [10], who found that in obese subjects physical activity may lower basal high levels of IFNgamma, is not possible due to the lack of recognition of physical activity in our population. On the other hand, looking at the levels of IFNs in our obese and control arms, they overlap with those expressed into literature [38].

The association between IMTG scores and HS at US grades could hypothetically explained on the ground of common mechanisms leading to ectopic fat storage and utilisation. Indeed, the reason for which there is a lack of link between IMTG and VAT remains a point to be further clarified: this no association is in agreement with the absence of correlation between IMTG scores and IR and in contrast with the apparent but not confirmed, when adjusted for VAT presence, association between IMTG and HS at US. Further study is needed, at the light that NAFLD is considered a CV risk factor [39] and could lead to hepatocarcinoma.
The importance of relation between IFNs and VAT is italics by a recent work stressing that type 1 IFN signature gene expression in VAT correlates with both adipose tissue and systemic IR in obese individuals [40].

Up-to-date results in mice provide genetic evidence that plasmacytoid dendritic cells via type I IFNs, regulate energy metabolism and promote the development of obesity [41]. A possible mechanism explaining the latter event could be the signalling pathway activated by type I IFNs [42].

Although fatty acids induced type I IFN responses in murine hepatocytes/macrophages and exposure to a high-fat diet elicited type I IFN-regulated gene expression in the liver of wild-type mice, modulating susceptibility to metabolic or hepatic disease [43], we were not able to confirm this important link of IFN-alpha 2 with HS in our population.

Among limitations to study, we firstly acknowledge that ours was an observational study in which a clear relation of cause and effect is not possible to find; secondly the hypothetical mechanisms are far to be elucidated, being mechanistic studies not carried out; thirdly not having evaluated the physical activity with appropriate tests, even though there no univocal concordance on which one should be performed, because lifestyle strategies differentially affect IMTG accumulation [44].

As final remark, considering that IFN-alpha alters the human intestinal mucosa immune homeostasis [45] and looking at the main role of gut microbiome in obesity, our observation deserve controlled research in order to confirm these preliminary data.

\section{Conclusion}

The complex interplay between cytokines and ectopic fat excess is hopefully enriched by the observation that in obese patients with NAFLD the serum levels of IFNalpha 2 are inversely related to IMTG scores, differently 


\section{from IFN-gamma levels that are not associated with severity of this ectopic storage.}

\section{Authors' contributions}

GT planned the study, analysed data and drafted manuscript. SC, FC and AS performed the immunological laboratory data. VC and PC gathered clinical data. DC contributed to drafting the manuscript and revised it critically as well other authors. All authors read and approved the final manuscript.

\section{Author details}

${ }^{1}$ Department of Clinical Medicine and Surgery, "Federico II" University Medical School of Naples, Naples, Italy. ${ }^{2}$ Oncology Research Center of Mercogliano (CROM), Istituto Nazionale Tumori-IRCSS-Fondazione G. Pascale, Naples, Italy. ${ }^{3}$ Department of General Medicine, "Umberto I"Hospital, Nocera Inferiore, SA Italy. ${ }^{4}$ "Federico II" University Medical School of Naples, Naples, Italy. ${ }^{5}$ Integrated Care Department of Public Health and Drug-Use, Section of Medical Pharmacology and Toxicology, "Federico II" University, Naples, Italy.

\section{Acknowledgements}

None.

\section{Competing interests}

The authors declare that they have no competing interests.

\section{Availability of data and materials}

The datasets generated and/or analysed during the current study are not publicly available due (data must be handled so as to not compromise study participants' privacy) but are available from the corresponding author on reasonable request.

\section{Consent for publication}

It is specified above.

\section{Ethics approval and consent to participate}

Ethics approval and consent has been waived to to the fact that was a substudy, which used the same original patient sample contained in a previous research (Tarantino G, Costantini S, Finelli C, Capone F, Guerriero E, La Sala N, Gioia S, Castello G. Carotid intima-media thickness is predicted by combined eotaxin levels and severity of hepatic steatosis at Ultrasonography in Obese Patients with Nonalcoholic Fatty Liver Disease. PLOS ONE. 2014;9: e105610, but with completely different analytical approaches resulting to be equally valid, according to The International Committee of Medical Journal Editors (ICMJE) at http://www.icmje.org/recommendations/browse/publishing-and-edito rial-issues/overlapping-publications.html.

\section{Funding}

There was no availability of funds from any organisation.

\section{Publisher's Note}

Springer Nature remains neutral with regard to jurisdictional claims in published maps and institutional affiliations.

Received: 21 September 2018 Accepted: 21 December 2018 Published online: 03 January 2019

\section{References}

1. Moro C, Galgani JE, Luu LC, Pasarica M, Mairal A, Bajpeyi S, Schmitz G, Langin D, Liebisch G, Smith SR. influence of gender, obesity, and muscle lipase activity on intramyocellular lipids in sedentary individuals. J Clin Endocrinol Metab. 2009:94:3440-7.

2. Watt MJ, Hoy AJ. Lipid metabolism in skeletal muscle: generation of adaptive and maladaptive intracellular signals for cellular function. Am J Physiol Endocrinol Metab. 2012;302:E1315-28.

3. Shaw CS, Clark J, Wagenmakers AJ. The effect of exercise and nutrition on intramuscular fat metabolism and insulin sensitivity. Annu Rev Nutr. 2010;30:13-34.
4. van Loon LJ, Koopman R, Manders R, van der Weegen W, van Kranenburg GP, Keizer HA. Intramyocellular lipid content in type 2 diabetes patients compared with overweight sedentary men and highly trained endurance athletes. Am J Physiol Endocrinol Metab. 2004;287:E558-65.

5. Akima H, Hioki M, Yoshiko A, Koike T, Sakakibara H, Takahashi H, Oshida Y. Intramuclular adipose tissue determined by T1-weighted MRI at 3T primarily reflects extramyocellular lipids. Magn Reson Imaging. 2016;34:397-403

6. Young Hui-Ju, Jenkins Nathan T, Zhao Qun, McCully Kevin K. Measurement of intramuscular fat by muscle echo intensity. Muscle Nerve. 2015:52:963-71.

7. Caresio C, Molinari F, Emanuel G, Minetto MA. Muscle echo intensity: reliability and conditioning factors. Clin Physiol Funct Imaging. 2015:35:393-403.

8. Li F, Li Y, Duan Y, Hu CA, Tang Y, Yin Y. Myokines and adipokines: involvement in the crosstalk between skeletal muscle and adipose tissue. Cytokine Growth Factor Rev. 2017;33:73-82.

9. Wentworth JM, Zhang JG, Bandala-Sanchez E, Naselli G, Liu R, Ritchie M, Smyth GK, Brien PE, Harrison LC. Interferon-gamma released from omental adipose tissue of insulin-resistant humans alters adipocyte phenotype and impairs response to insulin and adiponectin release. Int J Obes (Lond). 2017:41:1782-9.

10. Schmidt FM, Weschenfelder J, Sander C, et al. Inflammatory cytokines in general and central obesity and modulating effects of physical activity. PLOS ONE. 2015;10:e0121971.

11. Christeff NI, Melchior JC, de Truchis P, Perronne C, Gougeon ML. Increased serum interferon alpha in HIV-1 associated lipodystrophy syndrome. Eur J Clin Invest. 2002;32:43-50.

12. Nishimura S, Manabe I, Nagasaki M, Eto K, Yamashita H, Ohsugi M, Otsu M, Hara K, Ueki K, Sugiura S, Yoshimura K, Kadowaki T, Nagai R. CD8+ effector T cells contribute to macrophage recruitment and adipose tissue inflammation in obesity. Nat Med. 2009;15:914-20.

13. Teran-Cabanillas E, Montalvo-Corral M, Caire-Juvera G, Moya-Camarena SY, Hernández J. Decreased interferon- $a$ and interferon- $\beta$ production in obesity and expression of suppressor of cytokine signaling. Nutrition. 2013:29:207-12.

14. Noland RC. Exercise and regulation of lipid metabolism. Prog Mol Biol Transl Sci. 2015;135:39-74.

15. Gepner Y, Shelef I, Schwarzfuchs D, Cohen N, Bril N, Rein M, Tsaban G, Zelicha H, Yaskolka, Meir A, Tene L, Sarusy B, Rosen P, Hoffman JR, Stout JR, Thiery J, Ceglarek U, Stumvoll M, Blüher M, Stampfer MJ, Shai I. Intramyocellular triacylglycerol accumulation across weight loss strategies; substudy of the CENTRAL trial. PLOS ONE. 2017;12:0188431.

16. Tarantino G, Costantini S, Finelli C, Capone F, Guerriero E, La Sala N, Gioia S, Castello G. Carotid intima-media thickness is predicted by combined eotaxin levels and severity of hepatic steatosis at ultrasonography in obese patients with nonalcoholic fatty liver disease. PLoS ONE. 2014;9:e105610.

17. Matthews DR, Hosker JP, Rudenski AS, Naylor BA, Treacher DF, Turner RC. Homeostasis model assessment: insulin resistance and beta-cell function from fasting plasma glucose and insulin concentrations in man. Diabetologia. 1985;28:412-9.

18. Tarantino G, Colicchio P, Conca P, Finelli C, Di Minno MN, Tarantino M, et al. Young adult obese subjects with and without insulin resistance: what is the role of chronic inflammation and how to weigh it non-invasively? J Inflamm (Lond). 2009;6:6.

19. Katz A, Nambi SS, Mather K, Baron AD, Follmann DA, Sullivan G, Quon MJ. Quantitative insulin sensitivity check index: a simple, accurate method for assessing insulin sensitivity in humans. J Clin Endocrinol Metab. 2000;85:2402-10.

20. Webb M, Yeshua H, Zelber-Sagi S, Santo E, Brazowski E, Halpern Z, Oren R. Diagnostic value of a computerized hepatorenal index for sonographic quantification of liver steatosis. AJR Am J Roentgenol. 2009;192:909-14.

21. Armellini F, Zamboni M, Rigo L, Bergamo-Andreis IA, Robbi R, De Marchi $M$, Bosello $O$. Sonography detection of small intra-bdominal fat variations. Int J Obes. 1991;15:847-52.

22. Pillen S, Arts IMP, Zwarts MJ. Muscle ultrasound in neuromuscular disorders. Muscle Nerve. 2008;37:679-93.

23. Heckmatt JZ, Leeman S, Dubowitz V. Ultrasound imaging in the diagnosis of muscle disease. J Pediatr. 1982;10:656-60. 
24. Jenkins ND, Miller JM, Buckner SL, Cochrane KC, Bergstrom HC, Hill EC, Smith CM, Housh TJ, Cramer JT. Test-retest reliability of single transverse versus panoramic ultrasound imaging for muscle size and echo intensity of the biceps brachii. Ultrasound Med Biol. 2015;41:1584-91.

25. Tarantino G, Marra M, Contaldo F, Pasanisi F. Basal metabolic rate in morbidly obese patients with non-alcoholic fatty liver disease. Clin Invest Med. 2008;31:E24-9.

26. Schutz Y, Kyle UUG, Pichard C. Fat-free mass index and fat mass index percentiles in caucasians aged 18-98 y. Int J Obes. 2002;26:953-60.

27. Davison KK, Ford E, Cogswell M, Dietz W. Percentage of body fat and body mass index are associated with mobility limitations in people aged 70 and older from NHANES III. J Am Geriatr Soc. 2002;50:1802-9.

28. Kleiner G, Marcuzzi A, Zanin V, Monasta L, Zauli G. Cytokine levels in the serum of healthy subjects. Mediators Inflamm. 2013;2013:434010.

29. Baron RM, Kenny DA. The moderator-mediator variable distinction in social psychological research: conceptual, strategic and statistical considerations. J Pers Soc Psychol. 1986;51:1173-82.

30. Doerrler W, Feingold KR, Grunfeld C. Cytokines induce catabolic effects in cultured adipocytes by multiple mechanisms. Cytokine. 1994;6:478-84.

31. Feingold KR, Grunfeld C. Role of cytokines in inducing hyperlipidemia. Diabetes. 1992;41:97-101.

32. Feingold KR, Doerrler W, Dinarello CA, Fiers W, Grunfeld C. Stimulation of lipolysis in cultured fat cells by tumor necrosis factor, interleukin-1, and the interferons is blocked by inhibition of prostaglandin synthesis. Endocrinology. 1992;130:10-6.

33. Grunfeld C, Dinarello CA, Feingold KR. Tumor necrosis factor-a, interleukin-1, and interferon alpha stimulate triglycerides synthesis in HepG2 cells. Metabolism. 1991;40:894-8.

34. Feingold KR, Soued M, Serio MK, Moser AH, Dinarello CA, Grunfeld C. Multiple cytokines stimulate hepatic lipid synthesis in vivo. Endocrinology. 1989;125:267-74.

35. Shinohara E, Yamashita S, Kihara S, Hirano K, Ishigami M, Arai T, Nozaki S, Kameda-Takemura K, Kawata S, Matsuzawa Y. Interferon alpha induces disorder of lipid metabolism by lowering postheparin lipases and cholesteryl ester transfer protein activities in patients with chronic hepatitis $C$. Hepatology. 1997;25:1502-6.
36. Li M, Paran C, Wolins NE, Horowitz JF. High muscle lipid content in obesity is not due to enhanced activation of key triglyceride esterification enzymes or the suppression of lipolytic proteins. Am J Physiol Endocrinol Metab. 2011;300:E699-707.

37. Simonson DC. Surrogate measures of insulin resistance: does one size fit all? Diabetologia. 2015;58:207-10.

38. Azizian M, Mahdipour E, Mirhafez SR, Shoeibi S, Nematy M, Esmaily $H$, Ferns GA, Ghayour-Mobarhan M. Cytokine profiles in overweight and obese subjects and normal weight individuals matched for age and gender. Ann Clin Biochem. 2016;53:663-8.

39. Fargion S, Porzio M, Fracanzani AL. Nonalcoholic fatty liver disease and vascular disease: state-of-the-art. World J Gastroenterol. 2014;20:13306-24.

40. Ghosh AR, Bhattacharya R, Bhattacharya S, Nargis T, Rahaman O, Duttagupta P, Raychaudhuri D, Liu CS, Roy S, Ghosh P, Khanna S, Chaudhuri T, Tantia O, Haak S, Bandyopadhyay S, Mukhopadhyay S, Chakrabarti P, Ganguly D. Adipose recruitment and activation of plasmacytoid dendritic cells fuel metaflammation. Diabetes. 2016;65:3440-52.

41. Hannibal TD, Schmidt-Christensen A, Nilsson J, Fransén-Pettersson N, Hansen L, Holmberg D. Deficiency in plasmacytoid dendritic cells and type I interferon signalling prevents diet-induced obesity and insulin resistance in mice. Diabetologia. 2017;60:2033-41.

42. Uzé G, Schreiber G, Piehler J, Pellegrini S. The of the type I interferon family. Curr Top Microbiol Immunol. 2007:316:71-95.

43. Wieser V, Adolph TE, Grander C, Grabherr F, Enrich B, Moser P, Moschen AR, Kaser $\mathrm{S}$, Tilg H. Adipose type I interferon signalling protects against metabolic dysfunction. Gut. 2018;67:157-65.

44. Gepner Y, Shelef I, Schwarzfuchs D, Cohen N, Bril N, Rein M, Tsaban G, Zelicha H, Yaskolka Meir A, Tene L, Sarusy B, Rosen P, Hoffman JR, Stout JR, Thiery J, Ceglarek U, Stumvoll M, Blüher M, Stampfer MJ, Shai I. Intramyocellular triacylglycerol accumulation across weight loss strategies; substudy of the CENTRAL trial. PLOS ONE. 2017;12(11):e0188431.

45. Jarry A, Malard F, Bou-Hanna C, Meurette G, Mohty M, Mosnier JF, Laboisse CL, Bossard C. Interferon-alpha promotes Th1 response and epithelial apoptosis via inflammasome activation in human intestinal mucosa. Cell Mol Gastroenterol Hepatol. 2016;3:72-81.
Ready to submit your research? Choose BMC and benefit from:

- fast, convenient online submission

- thorough peer review by experienced researchers in your field

- rapid publication on acceptance

- support for research data, including large and complex data types

- gold Open Access which fosters wider collaboration and increased citations

- maximum visibility for your research: over 100M website views per year

At BMC, research is always in progress.

Learn more biomedcentral.com/submissions 